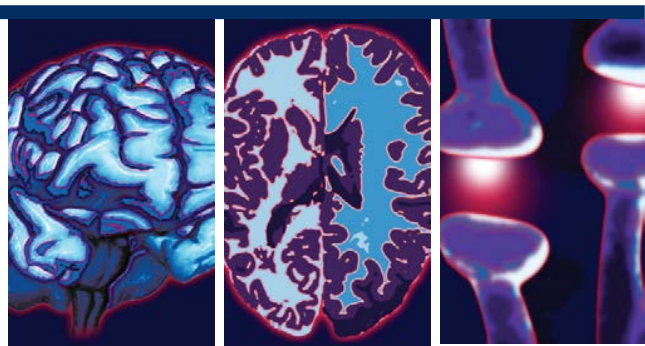

\title{
The Psychological and Spiritual Dimensions of Palliative Care: A Descriptive Systematic Review
}

\author{
Francisca Rego ${ }^{\dagger}$, Cândida Pereira, Guilhermina Rego, Rui Nunes
}

\begin{abstract}
Objective: To study the relationship between the psychological and spiritual dimensions in adult palliative care.

Methods: The data sources used were Medline, Web of Knowledge and Scopus, using the following key concepts: "palliative care" and "psychology" and "spirituality". The search took place 5th December 2017, at 10:20 am, and no articles were excluded based on publication date. Out of a total of 1038 articles found, 65 met the pre-selected criteria and were included in the descriptive qualitative synthesis.
\end{abstract}

Results: Some lack of definitional consensus of spirituality is still evident. Nevertheless, spiritual wellbeing was considered an important component of quality of life, closely related to physical and psychological distress symptoms, therefore highlighting the importance of psychological and psychiatric care in enhancing the wellbeing of palliative care patients.

Conclusion: Understanding the interface of the psychological and spiritual dimensions of adult palliative care patients may contribute to a more efficient therapeutic practice. Therefore, training healthcare professionals to improve spiritual support and appropriately addressing these issues should be of great importance in palliative care settings, thus promoting an appropriate response to the patients' needs and dying process.

\section{Keywords}

Hospice, Palliative Care, Psychology, Spirituality

\section{Introduction}

Palliative care advocates the idea of a holistic, comprehensive and patient-centred healing, thus supporting the biopsychosocial-spiritual model that was developed to address the totality of the patients' relational existence to the physical, psychological, social, and spiritual dimensions $[1,2]$. Indeed, spirituality has been identified as a significant dimension of quality of life and psychological wellbeing for patients at the endof-life $[3,4]$. However, the lack of agreement in the conceptualisation of spirituality still remains a problem in both research and clinical practice, often resulting in a non-systematic and intuitive approach to patients' spiritual needs $[5,6]$.

In nature, spiritual discussions are usually envisioned as existential or religious [7]. Essentially, spirituality can be defined as a "way individuals seek and express meaning and purpose, and the way they experience their connectedness to the moment, to self, to others, to nature and to the significant or sacred" [8].

At the end-of-life, it is common for patients to engage in exploring one's spirituality [5], and it is known that psychological and spiritual variables have an important effect mediating physical 
symptoms and suffering [9]. However, to understand the relationship between spirituality and psychological wellbeing, an understanding of the relationship between institutional religion and spirituality is necessary [10].

Although spirituality and religion are often seen as identical, important distinctions have been referred. Spirituality can exist both within or outside a religious context, as many individuals consider themselves spiritual and do not adhere to any particular religion [2,11]. Religion, on the other hand, denotes an organised system of beliefs, practices, and ways of worship [12] and although religion may be a way to express spirituality, some individuals focus less on the spiritual aspects of religion than on the traditions, social interactions and rituals $[13,14]$.

Previous research has demonstrated associations between psychological symptoms such as anxiety, depression and pain and spiritual wellbeing. However, these involve small numbers of patients and few have demonstrated effective interventions for spiritual wellbeing [15]. Also, a considerable overlap has been noted between the spiritual and the religious constructs in the measures used to assess spirituality [10]. So, there is evidence that spiritual needs are poorly assessed and met in clinical practice, which impacts patients' quality of life and satisfaction with care [16-19].

Patients' spirituality is known to impact on decision-making at the end-of-life, and high levels of spiritual wellbeing have been associated with improved quality of life, improved coping with disease, improved adjustment to diagnosis, better ability to cope with symptoms and protection against depression, hopelessness and desire of hastened death. Therefore, improving spiritual support in patients' palliative care is a valuable task [7].

In this sense, the aim of this descriptive systematic review is an updated analysis of the relationship between the psychological and spiritual dimensions of adult palliative care. As it is widely recognised spirituality is a multidimensional concept, integrated in the body and mind, that reflects a personal philosophy of life [20], thus meaning that all persons are spiritual beings and have spiritual needs that should be supported in their health care [21].

\section{Methods}

\section{- Search strategy}

The study started with a search of three databases,
Medline (PubMed), Web of Knowledge (ISI) and Scopus, using the following key concepts: "palliative care" and "psychology" and "spirituality". The search took place 5th December 2017, at 10:20 am, and no articles were excluded based on publication date. The aim of our search was to identify studies which explored the relationship between the spiritual and psychological dimensions in the context of adult palliative care. The key concepts resulted in 484 articles in PubMed, 377 articles in ISI and 163 articles in Scopus. Additionally, 14 studies were found after searching the references of articles included from the search of databases.

\section{- Inclusion criteria}

Only studies involving palliative care or hospice settings and a population of adult palliative care patients ( $\geq 18$ years old) were included. Empirical, quantitative and qualitative studies were also comprised.

\section{- Exclusion criteria}

Articles written in languages other than English or Portuguese were excluded, as well as studies including less than twenty participants. Studies that involved family members/ carers and/or healthcare professionals were also excluded, as well as those referring to settings other than palliative care or hospices, or including subjects younger than 18 years old. Editorials, letters to the editor, comments and narrative case reports were also excluded.

\section{- Quality assessment of studies and data extraction}

Study quality and eligibility were individually carried out by 3 researchers. Data extraction was done manually, without resorting to any extraction software. The results were subjected to critical review by 3 researchers (FR, CP, GR) and a coordinator (RN). Any differing opinions regarding articles' relevance were solved by reaching a consensus among the authors.

\section{Results}

From title and abstract analysis, 727 out of 1038 articles were excluded based on inclusion and exclusion criteria. In addition, 167 duplicate articles were excluded. A total of 144 full-text articles were analysed, of which 79 were excluded as they didn't meet the study criteria. A flow diagram following PRISMA guidelines [22] showing all literature procedures as well as the resulting number of articles selected is displayed in Figure 1. 
An overview of the 65 articles included in the descriptive qualitative synthesis is presented in Appendix 1, with the articles organised according to publication date, from 1996 to 2017. The following domains were analysed: general information; sample; the definition and / or measures of spirituality and the results regarding the relationship between the spiritual and psychological dimensions. The authors considered it relevant to identify the definition of spirituality and the measures used to assess this concept, given the unstandardized conceptualisation and assessment of spirituality described in the literature. Data gathered from the articles was summarised using percentages and frequencies for descriptive purposes.

\section{- Definitions of spirituality}

When addressing spirituality, the most frequent definitional concept mentioned was: the connection to the transcendent and search for purpose and meaning in life (goes beyond religious affiliation, it may be connected or not to a divine figure/religious faith) [4,21,23,2426], involved in the way people experience their connectedness to the moment, self, others, nature and to the significant or sacred [27-36] $(24,62 \% ; n=16)$ (Table 1). Nevertheless, half of the studies included in this review $(50,77 \%$; $\mathrm{n}=33$ ) didn't identify a definition for spirituality.

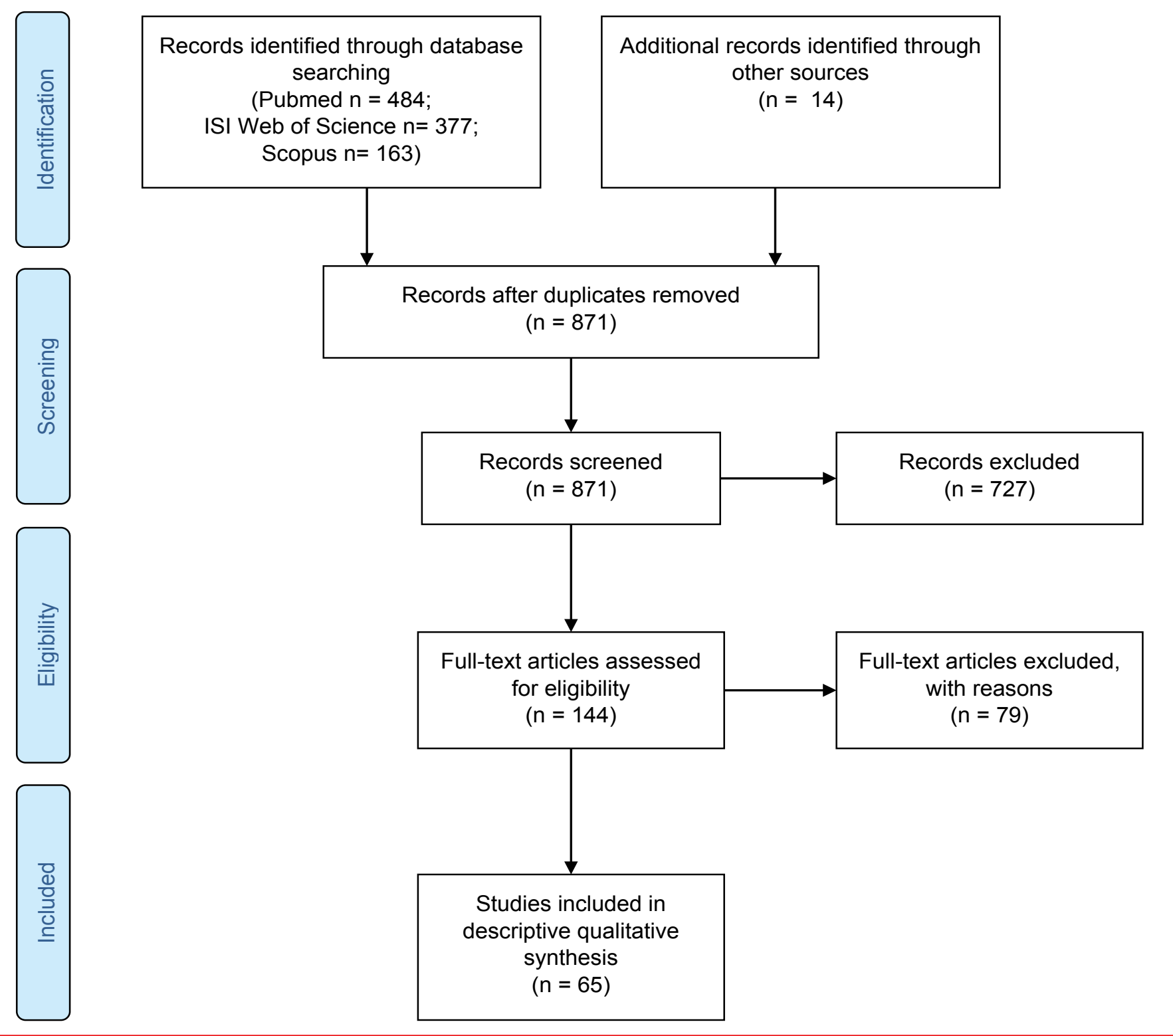

Figure 1: PRISMA flow diagram showing the literature method search. n: number of articles. 


\begin{tabular}{|c|c|c|}
\hline Definitions of Spirituality & $\begin{array}{l}\text { Number of articles } \\
\mathrm{N}=65\end{array}$ & $\%$ \\
\hline $\begin{array}{l}\text { Connection to the transcendent and search for purpose and meaning in life (goes beyond religious affiliation, it may } \\
\text { be connected or not to a divine figure/religious faith) }[4,21,23-26] \\
-\quad \text { involved in the way people experience their connectedness to the moment, self, others, nature and to the } \\
\text { significant or sacred [27-36], }\end{array}$ & 16 & 24.62 \\
\hline $\begin{array}{l}\text { The ultimate meaning of life }[10,37,39,40-42] \\
\text { - } \quad \text { characterised by the capacity to love, forgive, worship, to see beyond the current circumstances, and to tran- } \\
\text { scend suffering [43] }\end{array}$ & 6 & 9.23 \\
\hline $\begin{array}{l}\text { An energetic reality that adds impetus and creativity to healing and dying before any medically possible assessment } \\
\text { [44] }\end{array}$ & 1 & 1.54 \\
\hline $\begin{array}{l}\text { Search for the transcendence, peace, connectedness, hope, purpose and meaning in life, often obtained through } \\
\text { religious beliefs [45] }\end{array}$ & 1 & 1.54 \\
\hline Search for a connection to what is divine or sacred [46] & 1 & 1.54 \\
\hline $\begin{array}{l}\text { 2-dimensional construct: Intrinsic spirituality that measures the degree of personal intimate spiritual beliefs; Extrinsic } \\
\text { spirituality expressed by level of religious practice shared with the community [47] }\end{array}$ & 1 & 1.54 \\
\hline $\begin{array}{l}\text { 4-dimensional construct: as a religious system of beliefs and values; as life meaning, purpose and connection with } \\
\text { others; as a nonreligious system of beliefs and values; as metaphysical or transcendental phenomena. } 38\end{array}$ & 1 & 1.54 \\
\hline Connection to nature and pets [48] & 1 & 1.54 \\
\hline To be at peace with God and to pray [49] & 1 & 1.54 \\
\hline $\begin{array}{l}\text { Search and understanding meaning in life, that may involve: sustaining relationship with self and others; meaning } \\
\text { beyond one's self; meaning beyond immediate events; and explanation for events and experiences [36] }\end{array}$ & 1 & 1.54 \\
\hline $\begin{array}{l}\text { Philosophical, theological, or other important personal } \\
\text { beliefs from which participants drew comfort and solace [50] }\end{array}$ & 1 & 1.54 \\
\hline Spiritual pain as a pain deep in your soul/being, that is not physical [51] & 1 & 1.54 \\
\hline Total & 32 & 49,23 \\
\hline
\end{tabular}

When defining spirituality, McClain-Jacobson et al. also addressed religiosity, referring to two components, namely intrinsic religiosity - the integration of religion into one's complete life, and extrinsic religiosity - the use of religiosity for social connectedness [4]. However, many patients consider religion independent of spiritual need [37]. Not only those without religious affiliation expressed spiritual needs but also those with religious beliefs drew distinctions between ritual religious needs and spiritual needs [37].

Concerning patients' views on spirituality, it was observed that most participants found spirituality through their religious practice and connection to a higher power, as well as through connection with friends, family and acquaintances [21,33,38]. These connections provided participants with various benefits, including meaning and purpose in life, compassion toward others and a positive spiritual influence on those who survived lifethreatening illnesses $[21,33,38]$. Other patients also experienced spirituality within the structure and process of work or volunteer service, through communication, mediation and activities $[21,33,38]$.

\section{- Measures of spirituality}

The studies included in this review used various scales and interviews to measure spirituality in palliative care patients $(55.38 \% ; n=36)$ (Table 2).
However, the scale most frequently used was the Functional Assessment of Chronic Illness Theory - Spiritual Wellbeing Scale [4,26-29,34,3954], given the Peace of Mind factor (i.e., not having made a meaningful contribution, feelings of unfinished business and concerns about spiritual life), and the Existential Distress factor (i.e., not feeling like the person who they once were, not feeling worthwhile or valued, a change in appearance, not being able to carry out important roles, feeling life no longer has meaning, and feeling they are a burden) [54] $(18.46 \% ; n=12)$. Still, there were various studies who didn't use a validated measure of spirituality (44.62\%; $n=29)$.

\section{- Sample of the studies}

Regarding the influence of sociodemographic characteristics on spirituality, various studies found a significant association $(\mathrm{p}<.05)$ between younger age with worse spiritual outcomes and quality of life, as compared to older people [19,46,52-67]. That is, for younger patients, the possibility of a shortened life, of a decline in function and unfulfilled aspirations can become sources of great spiritual and psychosocial distress [43]. Increasing age was significantly related with better physical, psychological and existential scores $[45,66]$ as well as better end-oflife preparation [52]. 


\begin{tabular}{|c|c|c|}
\hline Measures of Spirituality & $\begin{array}{l}\text { Number of articles } \\
\mathrm{N}=65\end{array}$ & $\%$ \\
\hline $\begin{array}{l}\text { The Funtional Assessment of Chronic Illness Therapy - Spiritual Well-being Scale (FACIT-SWB) }[4,26-29,34,39 \text {, } \\
42,43,52,53,54\end{array}$ & 12 & 18,46 \\
\hline Spiritual Involvement and Beliefs Scale (SBIS) $[40,45,55,56]$ & 4 & 6.15 \\
\hline Existencial factory of MQOL $[57,58]$ & 2 & 3.08 \\
\hline Beliefs and Value Scale (BVS) $[59,60]$ & 2 & 3.08 \\
\hline Grupo de espiritualidad de la SECPAL questionnaire (GES) $[32,61]$ & 2 & 3.08 \\
\hline Spirit $[8,19,59]$ & 2 & 3.08 \\
\hline The Patient Dignity Inventory $[54,61]$ & 2 & 3.08 \\
\hline The Daily Spiritual Experience Scale [62] & 1 & 1.54 \\
\hline The Spiritual Needs Inventory Scale [63] & 1 & 1.54 \\
\hline Missoula-VITAS Quality of Life Index (MVQOLI) subscale transcendent [64] & 1 & 1.54 \\
\hline $\begin{array}{l}\text { European Organization for Research and Treatment of Treatment of Cancer (EORTC QLQ-C15-PAL) and the } \\
\text { comprehensive QoL Scale [41] }\end{array}$ & 1 & 1.54 \\
\hline Beliefs and Activities Spirituality Scale (BASS) [65] & 1 & 1.54 \\
\hline African Palliative Care Associations African Palliative Outcome Scale (APCA African POS) [66] & 1 & 1.54 \\
\hline Steinhauser Spiritual well-being survey [15] & 1 & 1.54 \\
\hline Edmonton Symptom Assessment Scale - FS51 & 1 & 1.54 \\
\hline The systems of Belief Inventory [47] & 1 & 1.54 \\
\hline Go Wish card game \& List of wishes/statements [49] & 1 & 1.54 \\
\hline Spiritual Questionnaire for Indian Palliative Care Patients35 & 1 & 1.54 \\
\hline Total & 36 & 55.38 \\
\hline
\end{tabular}

Concerning strong predictors of spirituality, female patients showed a greater spirituality scores [45], as well as intrinsic and extrinsic spirituality $(\mathrm{p}<.01)$ [47] and were more likely to be spiritually distresses and cling onto a divine support $(\mathrm{p}<.05)$ [35]. Male patients $(\mathrm{p}<.01)$ and young age $(\mathrm{p}<.05)$ were also found as significant predictors of high spirituality scores in another study [55], as well as years of education $(\mathrm{p}<0.05)$ $[35,45]$. Clinical variables such as chemotherapy [55] and radiotherapy [45] were also found as strong predictors of spirituality $(\mathrm{p}<.05)$.

\section{- Spiritual and psychological dimensions}

Spiritual wellbeing was specified as a central component of psychologic health [40]. It is important for patients at the end-of-life to keep psychological distress to a minimum, as a negative relationship between depression and spiritual wellbeing was noted in several studies [39]. an association between positive emotions and quality of life in connection with faith, rituals and associated prayers, and social interactions was highlighted [26,68,69]. Also, patients reported bad emotions, such as feelings of uselessness or fears about the future, which were strongly connected to restraints caused by illness, namely given to the decreasing health status, inability to work and pursue leisure activities [68,69]. For most patients, faith (as a possible subcategory of spirituality), peace and life worth (related to personal identity) influenced many areas of life $[26,68,70]$, as well as the family's future, their own future, death, livelihood, financial problems and disability $[15,23,35,68,69]$.

This way, the influence of spiritual wellbeing on the emotional and physical dimensions was enhanced in most studies [15,24,28,58,56], verifying significant associations between greater spiritual wellbeing and greater quality of life $[41,55,63,64]$ less depression $[9,10,28,40,43,70$ $72]$ less anxiety [26], [40,73], less fatigue and less pain $[26,35,43]$ - highlighting the importance of spirituality as a coping mechanism. Nevertheless, two studies found no significant associations between spirituality and psychological symptoms, namely anxiety and depression $[31,47]$. Also, it was found that patients with certain psychosocial and spiritual problems (e.g. propriety preparation problem, fear of death, and anxiety), tended to have specific physical symptoms (e.g. dyspnoea, fatigue) [28,31]. Thus, a poorer physical function was found predictive of worse physical, psychological and existential wellbeing [66].

The greatest form of spiritual distress mentioned by patients was the sense of dis-integrity, of not "being myself" [23]; worries about family $[23,68]$; hopelessness [55] and "feeling life no longer had meaning or purpose" - a variable predicting the sense of dignity, which is a 
concept that encompasses a wide spectrum of physical, psychosocial, spiritual, familial and cultural issues $[59,67]$.

Patients also reported that spirituality and religiosity helped them cope and served as a source of strength and comfort [27]. Spirituality, especially it's existential or "sense of meaning and purpose" dimension, was associated with less distress for palliative care patients [42]. The most common expression of spiritual integrity was the ability to help others, and to use the illness as an opportunity for personal growth and acceptance [23].

Concerning religiosity, some studies found negative aspects, such as negative religious coping (e.g. punishment or abandonment by God), as being positively associated with distress, confusion, depression, and negatively associated with physical and emotional wellbeing and quality of life $[53,40]$. Conversely, other studies pointed to the positive aspects of religiosity, which were mainly due to the social support resulting from religious practice, as receptivity by religious institutions is not only within their faith communities, but also in local neighbourhoods and service communities [74,75]. Therefore facilitating the acceptance of the illness condition, given the greater social support, and allowing them to share their feelings [47].

\section{Discussion}

We identified a total of 65 articles which met the pre-specified criteria for the descriptive qualitative synthesis. It has been noted the influence of demographic, mostly age and gender, and clinical characteristics on spirituality, however there is still few evidence This way, it is relevant to further explore these issues, and also their relation to the family life cycle and the experience of the illness.

Various definitions, views and measures on spirituality were underlined along the studies content analysis. Accordingly, patients' different philosophical beliefs and spiritual values of reason, mental discipline, dignity, communication, etc., supports the fact that individuals at the end-of-life approach spirituality from various perspectives [38].

Thus, besides the individual aspect, this diversity of views on spirituality is greatly related with culture. For instance, in India, spirituality seems to be strongly determined by the economic and religious context, which have to do with belief in fate and karma $[35,68]$. On the other hand, in Norway, people tend to consider God or a higher power more as a friend, collaborator and supporter, than as a universal and almighty God/ power [36]. Furthermore, the way illness and death are understood and expressed by individuals is culturally shaped [25]. For example, in Italian patients, faith, when discussed in traditionally religious term, is most helpful in determining patients' well-being at the end-of-life, and to help coping with unpleasant or unavoidable circumstances [26]. As for Indian patients, illness is generally seen as a punishment from God, and this is mostly noticeable in women, given their social and family roles in Indian society [35].

In part, this is due to the moral values, education and economy present in a particular culture. For instance in Scandinavian countries it is found collective and social democratic values, as well as free healthcare [36] and high global levels of education. While, in societies where not all patients have the opportunity to choose the best treatments and care because of their financial situation (e.g. USA, India), one way of coping is to believe that God controls the illness $[25,36]$.

So, healthcare professionals need to have in mind that various aspects of care, for instance decisionmaking regarding life-sustaining treatment, transplantation or end-of-life care/rituals, are often culturally based with spiritual or religious implications [76]. Also, acknowledging patients' specific demographic and medical characteristics may contribute to the prediction of patients' spiritual beliefs and attitudes [45]. This way, the importance of the role of culture and spirituality in the assessment and care planning at the endof-life is evident [76].

Also, given the cultural and contextual nature of spirituality, researchers should use questionnaires and scales carefully, as they have been developed in certain cultural contexts, and therefore can fail to capture specific aspects of spirituality in other regions [35]. Therefore, the need to have a universal definitional construct of spirituality that allows to encompass different cultures, is imperative (and further studies are needed in this field). This way, spirituality measures can be adapted and validated to all cultural contexts, considering their particular moral and cultural values, without losing the construct's main core.

As this review enabled to identify, the consensus between studies in the selection of scales to measure spirituality is still incipient, which can imply a lack of harmonisation in the assessment 
of spirituality, possibly given the lack of definitional specificity of spirituality that still exists $[10,54]$. It is important to highlight the fact that patients encounter particular difficulties with items directly pertaining to religion and spirituality, which may be an indicator of the underlying existential concerns patients deal with as they approach the end-of-life [5]. Thus, the administration of these measures may require the specific intervention of a mental health professional or spiritual care specialist, during and/or after its completion [5].

This review focused on the psychological dimensions present in palliative care context, in general. This way, it was possible to explore the work done on all variables in this dimension. Still, after content analysis of the articles included in this review, specific dimensions of psychology were highlighted, namely psychological wellbeing $[5,52,53,66,70]$, distress $[24,27,28,42,43,54,55]$ health [40], needs [73-77] and therapies $[44,50,61,78]$; anxiety $[15,26,28,31,40,47,49,6$ $0,61,62,65,77,79,80]$; depression $[10,15,28,31$ ,39,40,43,47,53,56,61,62,71,72,78]; desire for hastened death [4,39]; burden [50,53,60,67]; end-of-life despair [4,39,43]; coping strategies [9,26,35,30,36,75]; emotional wellbeing44, suffering [9,15,54, 72,68,81,82] and support [25]; dignity $[50,61,67,78]$ and quality of life $[26,34,41,51,57,58,61,63,64]$.

It is very common for palliative care patients to experience spiritual pain and suffering [19,71]. Spiritual pain, a pain deep in the soul/being that is not physical [51], can be expressed in different ways, namely as an intrapsychic conflict, as interpersonal loss or conflict, or in relation to the divine [19]. Spiritual suffering is more common in the presence of certain risk factors, as multiple losses, complete dependence, poor support, intense symptoms, excessive rumination, and non-acceptance, whereas good support, wellpalliated symptoms, resilience, optimism, appreciation and acceptance can be considered protective factors $[35,82]$. Therefore, special attention to certain dimensions, such as early palliative measures, family support, effective coping strategies, close relationships, feeling at peace and having a sense of meaning in life may enhance spiritual wellbeing $[64,67,78]$.

As the biopsychosocial-spiritual model suggests, all these dimensions (physical, psychological, social and spiritual) play an important role in patients' wellbeing [1], as well as the interactions between them, which cannot be neglected. The physical dimension (pain, asthenia, physical distress, and loss of autonomy) has an influence on suffering through the presence of emotional distress indicators - the psychological dimension (anxiety, depression, anhedonia, and altered mood), which predicts the level of adjustment to problems through the type of coping strategies chosen and the impact on the spiritual dimension. Thus, the influence of the spiritual dimension (hopelessness, desire for death, and loss of meaning in life) on suffering is mediated by the type of coping and the magnitude of the adjustment to problems [9].

This way, it can be acknowledged that psychological and spiritual variables have an important effect mediating patients' wellbeing, physical symptoms and suffering [9]. As pain and uncontrolled symptoms can limit a patient's ability to have meaningful interactions with others, possibly resulting in alienation [43]. this way hindering the search for meaning at the endof-life, causing spiritual distress [43].

Also, spirituality may have a much more powerful effect on psychological functioning than beliefs held about an afterlife [4], given that it is a supportive reality for many palliative care patients, turning them into more empathic and calm individuals [44]. Hence, supporting palliative care patients' spiritual and certain religious copings will reduce psychological symptoms and improve quality of life $[30,39,65]$.

However, spiritual care is not routinely provided at palliative care centres, and can be greatly influenced by the religious backgrounds of patients and of palliative care centers [41]. And, the lack of perceived understanding of these issues by healthcare professionals may influence patients' spiritual distress [24].

The support from hospital staff is required for helping patients move from spiritual distress to spiritual integrity [23], given that patients want healthcare professionals to broach these issues $[41,74]$, and to spend time with a healthcare professional who would listen to their stories, indicating that what was being sought was not so much religious intervention as human compassion [71].

This way, palliative care professionals may increase spiritual wellbeing in routine care, improving patients' sense of being at peace [15]. For that reason, the spiritual dimension of therapeutic assistance (e.g. music therapy and body relaxation) is of great importance, mainly 
in matters of meaning and hope in life crisis and despair [44], given that patients' spiritual experiences indicate a new wholeness, integrity and new mental and emotional consciousness [44].

There were three main psychotherapeutic interventions referred for the improvement of palliative care patients' wellbeing: counselling, dignity therapy and life review. The efficacy of counselling and dignity therapy has been reported due to the positive effect on perception of meaning in life, quality of life, and spiritual wellbeing $[61,78]$. Counselling intervention, one of the most widely reported therapies in the literature, has indicated better results for depression and resilience, as well as a significantly higher effect on anxiety [61].

Dignity therapy aims to increase sense of meaning, purpose, and dignity, while reinforcing a continued sense of worth within a supportive, nurturing, and accessible framework for those near end-of-life, through the process of creating a generativity/legacy document $[61,50]$. This intervention was found helpful to patient's family, and correlated with a more meaningful life and having a sense of purpose, less suffering and increased will to live, with post intervention measures of suffering showing significant improvement and reduced depressive symptoms [61]. Also, the use of generativity/ legacy documents in dignity therapy as shown prevalence in sense of legacy, fighting spirit and hope of palliative care patients [50].

Life review sessions, which aim to improve the sense of meaning, purpose, and acceptance through a progressive review of the lifespan and its most salient narratives [50], provided participants with an opportunity to discuss their heritage and legacy, interpersonal disappointments, regret, meaning and unfinished business, resulting in a future orientation. Intervention participants showed improvements in functional status, anxiety, depression, and preparation for end-oflife $[50,62]$. Concerning the need to reinterpret a person's life, it was observed that patients tended to make a positive and significant revision of their past, which helped them recover their selfesteem [83].

This way, it is evident the positive interaction between the psychological and spiritual dimensions in palliative care, as well as the influence of personal integrity and identity on spiritual wellbeing. Therefore, these issues should be properly and adequately addressed in palliative care settings. However, further studies should be conducted in order to determine the effectiveness of these therapies at a global level, and in different cultural contexts.

\section{Conclusions}

Some lack of definitional consensus of spirituality is still evident, given the few studies which identified a definition for spirituality and made a proper distinction between religion and spirituality. However, some progress in this matter can be observed, as various studies acknowledge that religious needs were different from spiritual needs [37].

Spirituality was perceived to be a broad concept expressed both humanely and religiously [74]. The main beneficial aspect of spirituality reported was related to one's ability to search internally for strength and meaning, and to place their illness in a broader context and accept their circumstances [10]. Therefore, enhancing patients' knowledge of themselves and of their own lives after the life-threatening illness [21], $[33,38]$. To note that religion also plays an important role, as it integrates the dimension of spirituality and is also associated with improved quality of life [30]. These positive aspects reside on the underlying social benefits of religious practice, as well as on those primarily related to spiritual wellbeing [10].

Spiritual wellbeing was reported as an important component of quality of life, physical and psychological wellbeing in palliative care patients, thus supporting a regular spiritual assessment, as part of the interdisciplinary approach to optimise care $[43,63]$.

The powerful effect of spiritual wellbeing on psychological distress was often referred, pointing to the important implications for treatment, especially to the significance of psychological therapies in enhancing the wellbeing of palliative care patients [61]. Also, a spiritual screening should ideally be set within a larger psychosocial assessment that includes all palliative care domains, such as patients' social supports and cultural background, screening for psychiatric issues and social needs [25,30]. Therefore, interventions should foster patients' spiritual wellbeing and help develop a sense of meaning in life and peace, resulting in substantial benefits for improving mental health at the end-of-life [55]. 
It is important to consider routine spiritual assessments to identify patients' needs, particularly in those with refractory symptoms [27], as a depersonalised and depersonalising system of care can add psychological distress to the personal burden of dealing with illness, as well as loss of a sense of being in control60. Care for psychosocial and spiritual health needs is part of an effective palliation and so, healthcare professionals should be competent in providing individualised spiritual care $[37,73]$, comprising the patient as a whole, demonstrating cultural inclusiveness, and promoting an appropriate response to the patient's needs and to the dying process $[2,84,85]$.

\author{
Acknowledgments \\ We would like to thank Professor António Moreira, \\ University of Aveiro, Portugal and Professor José \\ Pedro Nunes, University of Porto, Portugal, for \\ their help and guidance.
}

\section{Conflicts of Interest}

The author(s) declare no potential conflicts of interest with respect to the research, authorship and/or publication of this article.

\section{References}

1. Sulmasy D. A biopsychosocial-spiritual model for the care of patients at the end of life. Gerontologist 42(3), 24-33 (2002).

2. Rego F, Nunes R. The interface between psychology and spirituality in palliative care. J. Health. Psychol (2016).

3. Schuler SA. World Health Organization. Cancer pain relief and palliative care: report of a WHO expert committee, Geneva, Switzerland 1983.

4. McClain JC, Rosenfeld B, Kosinski A, et al. Belief in an afterlife, spiritual well-being and end of life despair in patients with advanced cancer. Gen. Hosp. Psychiatry 26(6), 484-486 (2004).

5. Lucette A, Brédart A, Vivat B, et al. Pilot-testing the French version of a provisional European Organisation for Research and Treatment of Cancer (EORTC) measure of spiritual wellbeing for people receiving palliative care for cancer. Eur. J. Cancer. Care 23(2), 221-227 (2014).

6. Narayanasamy A, Owens J. A critical incident study of nurses' responses to the spiritual needs of their patients. J. Adv. Nurs 4(1), 446455 (2001).

7. Best $M$, Butow $P$, Olver I. et al. The doctor's role in helping dying patients with cancer achieve peace: A qualitative study. Palliat. Med 28(9), 1139-1145 (2014).

8. Puchalski CM, Ferrel B, Virani R, et al. Improving the quality of spiritual care as a dimension of palliative care: the report of the consensus conference. J. Palliat. Med 12(1), 885-904 (2009).

9. Krikorian A, Limonero JT, Roman JP, et al. Predictors of Suffering in advanced cancer. Am. J. Hosp. Palliat. Med 31(5), 534-542 (2014).

10. Nelson CJ, Rosenfeld B, Breitbart W, et al. Spirituality, religion, and depression in the terminally III. Psychosomatics 43(3), 213-220 (2002).

11. Ellerhorst RJM. Measuring aspects of spirituality. Instruments or Clinical Nursing Research. Appleton and Lange 141-149 (1988).

12. Emblen JD. Religion and spirituality defined according to current use in nursing literature. J. Prof. Nurs 8(1), 41-47 (1992).

13. Elkins $D$, Hedstrom $L$, Hughes $L$, et al. Toward a humanistic phenomenological spirituality. $J$. Humanist. Psychol 28(1), 5-18 (1988).

14. Miller W, Thoresen C. Spirituality, religion, and health. An emerging research field. $A m$. Psychol 58(1),24-35 (2003).

15. Rabow MW, Knish SJ. Spiritual well-being among outpatients with cancer receiving concurrent oncologic and palliative care. Support. Care. Cancer 23(4), 919-923 (2015).

16. Clark $P$, Drain $M$, Malone $M$, et al. Addressing patients' emotional and spiritual needs. Jt Comm J Qual Saf 29(12), 659-670 (2003).

17. Heyland D, Cook D, Rocker G, et al. Defining priorities for improving end-of-life care in Canada. CMAJ 182(16), 747-752 (2010).

18. Kristeller J, Zumbrun C, Schilling R, et al. "I would if I could"': how oncologists and oncology nurses address spiritual distress in cancer patients. Psychooncology 8(5), 451-458 (1999).

19. Selman L, Siegert RJ, Higginson IJ, et al. The "spirit 8" successfully captured spiritual wellbeing in african palliative care: factor and rasch analysis. J. Clin. Epidemiol 65(4), 434-443 (2012).

20. Mok E, Wong F, Wong D, et al. The meaning of spirituality and spiritual care among the Hong Kong Chinese terminally ill. J. Adv. Nurs 66(2), 360-370 (2010).

21. Yong J, Kim J, Han SS, et al. Development and validation of a scale assessing spiritual needs for Korean patients with cancer. J. Palliat. Care 24(4), 240-246 (2008).

22. Moher $D$, Liberati $A$, Tetzlaff $A$, et al. The PRISMA group. preferred reporting items for systematic reviews and meta-analyses: the PRISMA statement. PLoS. Med 6(7) (2009).

23. Buxton F. Spiritual distress and integrity in palliative and non-palliative patients. Br. J. Nurs 16(15), 920-924 (2007).

24. Murray SA, Kendall M, Grant E, et al. Patterns of Social, Psychological, and Spiritual Decline Toward the End of Life in Lung Cancer and Heart Failure. J. Pain. Symptom. Manage 34(4), 393-402 (2007).

25. Koffman J, Morgan M, Edmonds P, et al. "I know he controls cancer": The meanings of religion among black caribbean and white british patients with advanced cancer. Soc. Sci. Med 67(5), 780-789 (2008).

26. Bovero $A$, Leombruni $P$, Miniotti $M$, et al. Spirituality, quality of life, psychological adjustment in terminal cancer patients in hospice. Eur. J. Cancer .Care 25(6), 961-969 (2016).

27. Delgado GMO, Hui D, Parsons HA, et al. Spirituality, religiosity, and spiritual pain in advanced cancer patients. J. Pain. Symptom. Manage. 2011;41(6):986-994. doi:10.1016/j. jpainsymman.2010.09.017.

28. Kandasamy A, Chaturvedi S, Desai G. Spirituality, distress, depression, anxiety, and quality of life in patients with advanced cancer. Indian J Cancer. 2011;48(1):55. doi:10.4103/0019-509X.75828.

29. Trinkaus M, Burman D, Barmala N, et al. Spirituality and use of complementary medicines for cure in advanced cancer. Psychooncology 20(7), 746-754 (2011).

30. Vallurupalli M, Lauderdale K, Balboni M, et al. The role of spirituality and religious coping in the quality of life of patients with advanced 
cancer receiving palliative radiation therapy. J. Support. Oncol 10(2), 81-87 (2012).

31. King $M$, Llewellyn $H$, Leurent $B$, et al. Spiritual beliefs near the end of life: a prospective cohort study of people wuth cancer receiving palliative care. Psychooncology 22(11), 2505-2512 (2013).

32. Benito E, Oliver A, Galiana L, et al. Development and validation of a new tool for the assessment and spiritual care of palliative care patients. J. Pain. Symptom. Manage 47(6), 1008-1018 (2014).

33. Young WC, Nadarajah SR, Skeath PR, et al. Spirituality in the context of life-threatening illness and life-transforming change. Palliat. Support. Care 13(3), 653-660 (2015).

34. Vermandere $M$, Warmenhoven F, Van Severen $\mathrm{E}$, et al. Spiritual history taking in palliative home care: A cluster randomized controlled trial. Palliat. Med 30(4), 338-350 (2016).

35. Gielen J, Bhatnagar S, Chaturvedi SK, et al. Prevalence and nature of spiritual distress among palliative care patients in india. J. Relig. Health 56(2), 530-544 (2017).

36. Rohde G, Kersten C, Vistad I, et al. Spiritual well-being in patients with metastatic colorectal cancer receiving noncurative chemotherapy. Cancer. Nurs 40(3), 209-216 (2017).

37. Yardley S, Walshe C, Parr A et al. Improving training in spiritual care: a qualitative study exploring patient perceptions of professional educational requirements. Palliat. Med 23(7), 601-607 (2009).

38. Dobratz MC. "All my saints are within me": expressions of end-of-life spirituality. Palliat. Support. Care 11(3), 191-198 (2013).

39. McClain CS, Rosenfeld B, Breitbart W, et al. Effect of spiritual well-being on end-of-life despair in terminally-ill cancer patients. Lancet 361(9369), 1603-1607 (2003).

40. Mystakidou K, Tsilika E. Assessing Spirituality and Religiousness. Am. J. Hosp. Palliat. Care 457-463 (2007).

41. Kang J, Shin DW, Choi JY, et al. Addressing the religious and spiritual needs of dying patients by healthcare staff in Korea: Patient perspectives in a multi-religious Asian country. Psychooncology 21(4), 374381 (2012).

42. Chochinov HM, Hassard T, McClement $S$, et al. The landscape of distress in the terminally III. J. Pain. Symptom. Manage 38(5), 641-649 (2009).

43. Hui D, Cruz M, Thorney S, et al. The frequency and correlates of spiritual distress among patients with advanced cancer admitted to an acute palliative care unit. Am. J. Hosp. Palliat. Med 28(4), 264-270 (2011).
44. Renz M, Schütt MM, Cerny T, et al. Spirituality, psychotherapy and music in palliative cancer care: Research projects in psycho-oncology at an oncology center in switzerland. Support. Care. Cancer 13(12), 961-966 (2005).

45. Mystakidou K, Tsilika E, Parpa E, et al. Demographic and clinical predictors of spirituality in advanced cancer patients: A randomized control study. J. Clin. Nurs 17(13), 1779-1785 (2008).

46. Alcorn SR, Balboni MJ, Prigerson HG, et al. "If God wanted me yesterday, i wouldn't be here today": religious and spiritual themes in patients' experiences of advanced cancer. J. Palliat. Med 13(5), 581-588 (2010).

47. Lai C, Luciani M, Galli F, et al. Spirituality and awareness of diagnoses in terminally III patients with cancer. Am. J. Hosp. Palliat. Med 34(6), 5-9 (2017).

48. Aoun S, Deas K, Skett K, et al. Older people living alone at home with terminal cancer. Eur. J. Cancer. Care 25(3), 356-364 (2016).

49. Delgado GMO, Rodriguez NA, Cruz V, et al. Advanced cancer patients' reported wishes at the end of life: a randomized controlled trial. Support. Care. Cancer 24(10), 42734281 (2016)

50. Vuksanovic D, Green H, Morrissey S, et al. Dignity therapy and life review for palliative care patients: a qualitative study. J. Pain. Symptom. Manage 54(4), 530-537 (2017).

51. Delgado GMO, Chisholm G, Williams J, et al. Frequency, intensity, and correlates of spiritual pain in advanced cancer patients assessed in a supportive/palliative care clinic. Palliat. Support. Care 14(4), 341-348 (2016).

52. Wentlandt K, Burman D, Swami N, et al. Preparation for the end of life in patients with advanced cancer and association with communication with professional caregivers. Psychooncology 876(1), 868-876 (1995).

53. Hills J, Paice J, Cameron J, et al. Spirituality and distress in palliative care consultation. J. Palliat. Med 8(4), 782-788 (2005).

54. Chochinov HM, Hassard T, McClement S, et al. The patient dignity inventory: a novel way of measuring dignity-related distress in palliative care. J. Pain. Symptom. Manage 36(6), 559-571 (2008)

55. Mystakidou K, Tsilika E, Prapa E, et al. Predictors of spirituality at the end of life. Can. Fam. Physician 54(12), 1720-1721 (2008).

56. Mystakidou K, Tsilika E, Parpa E, et al. Exploring the Relationships Between Depression, Hopelessness, Cognitive Status, Pain, and Spirituality in Patients With Advanced Cancer. Arch. Psychiatr. Nurs 21(3), 150-161 (2007)
57. Cohen S, Mount B, Tomas J, et al. Existential well-being is an important determinant of quality of life. Cancer 77(3), 576-586 (1996).

58. Cohen S, Mount B. Living with cancer: "good" days and "bad" days - what produces them? Cancer 89(8), 1854-1865 (2000).

59. Ho AHY, Chan CLW, Leung PPY, et al. Living and dying with dignity in chinese society: perspectives of older palliative care patients in hong kong. Age. Ageing 42(4), 455-461 (2013).

60. Reeve J, Lynch T, Lloyd WM, et al. From personal challenge to technical fix: the risks of depersonalised care. Heal. Soc. Care. Community 20(2), 145-154 (2012).

61. Rudilla D, Galiana L, Oliver A, et al. Comparing counseling and dignity therapies in home care patients: A pilot study. Palliat. Support. Care 14(4), 321-329 (2016).

62. Steinhauser KE, Alexander SC, Byock IR, et al. Do preparation and life completion discussions improve functioning and quality of life in seriously III patients? pilot randomized control trial. J. Palliat. Med 11(9), 1234-1240 (2008).

63. Buck HG, Overcash J, McMillan SC, et al. The geriatric cancer experience at the end of life: testing an adapted model. Oncol. Nurs. Forum 36(6), 664-673 (2009).

64. Selman LE, Higginson IJ, Agupio G, et al. Quality of life among patients receiving palliative care in south africa and uganda: a multi-centred study. Health. Qual. Life. Outcomes 9(1), 21(2011).

65. Gaudette H, Jankowski KRB. Spiritual coping and anxiety in palliative care patients: a pilot study. J. Health. Care Chaplain 19(4), 131-139 (2013).

66. Harding R, Powell RA, Namisango E, et al. Palliative care-related self-report problems among cancer patients in east africa: a twocountry study. Support. Care. Cancer 22(12), 3185-3192 (2014)

67. Chochinov HM, Krisjanson LJ, Hack TF, et al. Dignity in the terminally III: revisited. J. Palliat. Med 9(3), 666-672 (2006).

68. Elsner F, Schmidt J, Rajagopal M, et al. Psychosocial and spiritual problems of terminally ill patients in kerala, india. Futur. Oncol 8(9), 1183-1191 (2012).

69. Fegg MJ, Brandstätter $M$, Kramer $M$, et al. Meaning in life in palliative care patients. J. Pain. Symptom. Manage 40(4), 502-509 (2010).

70. Selman L, Speck P, Gysels M, et al. "Peace" and "life worthwhile" as measures of spiritual well-being in african palliative care: a mixed-methods study. Health. Qual. Life. Outcomes 11(1), 94 (2013). 
71. Mako C, Galek K, Poppito SR, et al. Spiritual pain among patients with advanced cancer in palliative care. J. Palliat. Med 9(5), 1106-1113 (2006).

72. Shah M, Quill T, Norton S, et al. "What bothers you the most?" initial responses from patients receiving palliative care consultation. $\mathrm{Am}$. J. Hosp. Palliat. Med 25(2), 88-92 (2008).

73. Mishra S, Bhatnagar S, Philip FA, et al. Psychosocial concerns in patients with advanced cancer: an observational study at regional cancer centre, india. Am. J. Hosp. Palliat. Med 27(5), 316-319 (2010).

74. Kernohan WG, Waldron M, McAfee C, et al. An evidence base for a palliative care chaplaincy service in Northern Ireland. Palliat. Med 21(6), 519-525 (2007).

75. Francoeur RB, Payne R, Raveis VH, et al. Palliative care in the Inner City: Patient religious affiliation, underinsurance, and symptom attitude. Cancer 109(2), 425-434
(2007).

76. Long C. Cultural and spiritual considerations in palliative care. J. Pediatr. Hematol. Oncol 33(2), 96-101 (2011).

77. Wijk H, Grimby A. Needs of elderly patients in palliative care. Am. J. Hosp. Palliat. Med 25(2), 106-111 (2008).

78. Chochinov HM, Hack T, Hassard T, et al. Dignity therapy: A novel psychotherapeutic intervention for patients near the end of life. J. Clin. Oncol 23(24), 5520-5525 (2005).

79. Pituskin E, Fairchild A, Dutka J, et al. Multidisciplinary team contributions within a dedicated outpatient palliative radiotherapy clinic: A prospective descriptive study. Int. J. Radiat. Oncol. Biol. Phys 78(2), 527-532 (2010).

80. Ho C Te, Hsu HS, Li Cl, et al. Certain biopsychosocial-spiritual problems associated with dyspnea among advanced cancer patients in Taiwan. Support. Care. Cancer 20(8), 1763-1770 (2012).
81. Blinderman CD, Cherny NI. Existential issues do not necessarily result in existential suffering: lessons from cancer patients in Israel. Palliat. Med 19(5), 371-380 (2005).

82. Beng TS, Guan NC, Seang LK, et al. The experiences of suffering of palliative care patients in malaysia: a thematic analysis. Am. J. Hosp. Palliat. Med 31(1), 45-56 (2014).

83. Vilalta A, Valls J, Porta J, et al. Evaluation of spiritual needs of patients with advanced cancer in a palliative care unit. J. Palliat. Med 17(5), 592-600 (2014).

84. Shafranske $\mathrm{E}$, Malony $\mathrm{H}$. Religion and the clinical practice of psychology: A case for inclusion. In: religion and the clinical practice of psychology, Washington DC: american psychological association, 561-586 (1996).

85. Moss E, Dobson K. Psychology, spirituality and end-of-life care: An ethical integration? Can. Psychol 47(1), 284-299 (2006). 